\title{
Comparação entre o uso tópico do fumarato de cetotifeno $0,025 \%$ e do cloridrato de olopatadina $0,1 \%$ no tratamento da ceratoconjuntivite primaveril
}

\author{
Comparative study between 0.025\% ketotifen fumarate and $0.1 \%$ olopatadine \\ hydrochloride in the treatment of vernal keratoconjunctivitis
}

\author{
Wilson Takashi Hida ${ }^{1}$ \\ Daniel Cruz Nogueira ${ }^{2}$ \\ Arthur Schaefer ${ }^{3}$ \\ Paulo Elias Correa Dantas ${ }^{4}$ \\ Maria Cristina Nishiwaki Dantas ${ }^{5}$
}

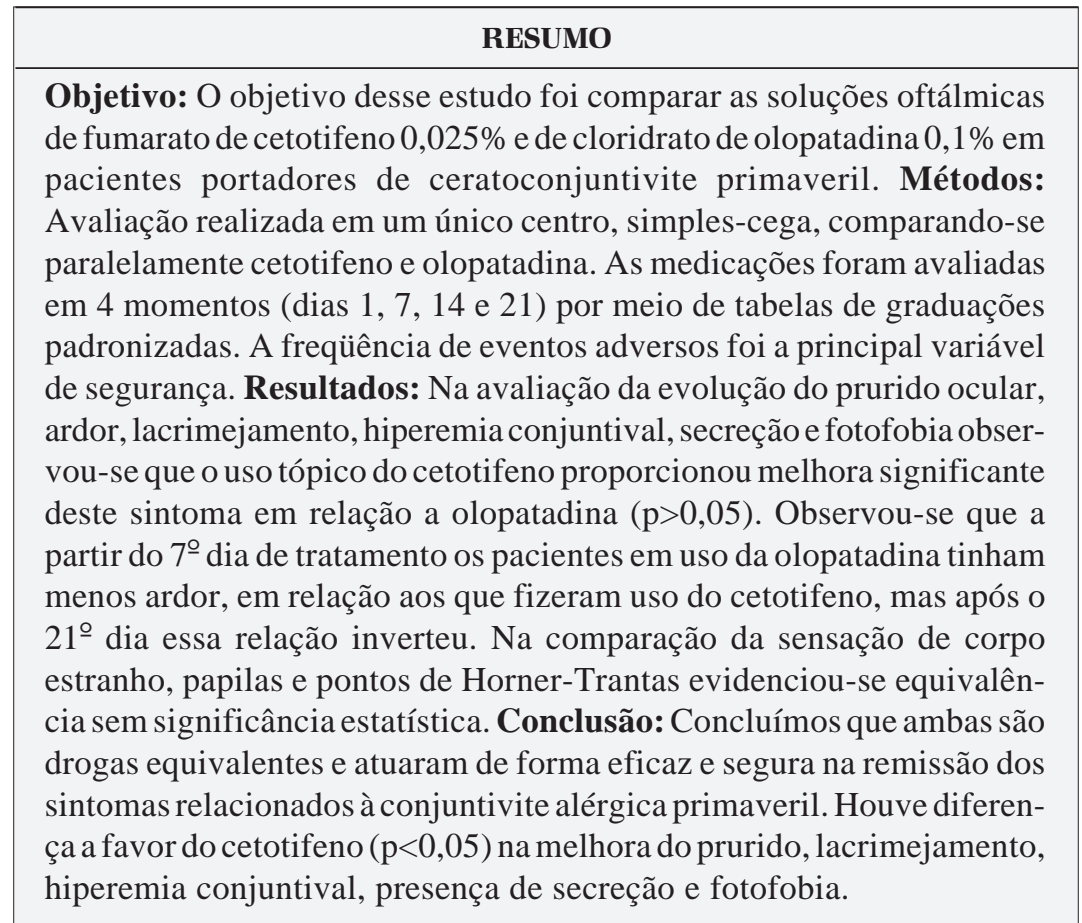

Descritores: Conjuntivite alérgica/quimioterapia; Cetotifeno/uso terapêutico; Soluções oftálmicas; Dibenzoxepinas/uso terapêutico; Combinação de medicamentos

\section{INTRODUÇÃO}

A ceratoconjuntivite primaveril (CCP) é uma afecção alérgica, crônica e bilateral, que acomete principalmente crianças em idade escolar, entre 7 e 10 anos de idade, do sexo masculino. É mais freqüente em regiões de clima quente e seco. Os sintomas, embora possam estar presentes o ano todo, intensificam-se na primavera e no verão. Tende a ter resolução espontânea após 2 a 8 anos de doença ativa ${ }^{(1)}$.

A CCP, por ser uma das variantes mais graves das conjuntivites alérgicas, deve ser diagnosticada e tratada apropriadamente. No ambulatório de Alergia Ocular da Santa Casa de São Paulo, corresponde a mais da metade de todos os casos atendidos ${ }^{(2)}$.

A prescrição de medicações tópicas tem sido a principal terapia para a conjuntivite alérgica, com objetivo de promover conforto imediato e tardio do paciente $^{(3)}$. 
São utilizadas drogas estabilizadoras de mastócitos, antiinflamatórios não hormonais e hormonais e anti-histamínicos locais e sistêmicos ${ }^{(4)}$.

Drogas tópicas de ação dupla ou múltipla combinam o conforto imediato do anti-histamínico tópico e tardio dos estabilizadores das células de mastócitos ${ }^{(5)}$.

Cloridrato de olopatadina é um agente tópico freqüentemente usado com ação de bloqueio dos receptores histamínicos H1 e estabilizadores das membranas de mastócitos ${ }^{(6-8)}$.

Fumarato de cetotifeno, além das ações já descritas para olopatadina, é também inibidor de migração de eosinófilos ${ }^{(3,5,9)}$.

Estudos recentes compararam olopatadina com placebo na conjuntivite alérgica crônica, correlacionando o seu mecanismo de ação com a diminuição da hiperemia conjuntival e prurido ${ }^{(10)}$.

Outros trabalhos compararam o cetotifeno $0,025 \%$ com placebo na conjuntivite alérgica em criança, demonstrando a sua eficácia primária na melhora do prurido ocular nesses pacientes ${ }^{(11-12)}$.

Na literatura revisada apontaram a superioridade do cetotifeno sobre a olopatadina na conjuntivite alérgica sazonal e outros estudos relataram o mesmo resultado nas conjuntivites alérgicas em geral, sem distinção quanto ao tipo de alergia ocular ${ }^{(13-14)}$.

Outros estudos demonstraram superioridade da olopatadina ao cetotifeno no conforto ocular a conjuntivite alérgica sazonal e perene $\mathrm{e}^{(15-16)}$.

Alguns trabalhos observaram superioridade da olopatadina sobre o cetotifeno, por meio de teste provocativo com alérgenos detectados no teste dermatológico ${ }^{(17)}$.

Não encontramos na literatura estudo comparando o uso tópico do cetotifeno com a olopatadina na CCP.

\section{OBJETIVO}

O objetivo deste estudo foi comparar o resultados do uso das soluções oftálmicas de fumarato de cetotifeno e de cloridrato de olopatadina em portadores de CCP.

\section{MÉTODOS}

\section{1) Desenho do estudo}

A avaliação foi realizada em um único centro, simplescega, comparando-se paralelamente uma solução oftálmica de fumarato de cetotifeno $0,025 \%$ com uma de cloridrato de olopatadina $0,1 \%$. Foi realizado no período de $1^{\circ}$ de setembro de 2004 a 15 de outubro de 2005, no setor de Alergia Ocular do Departamento de Oftalmologia da Santa Casa de São Paulo. Cada paciente foi esclarecido sobre o conteúdo do protocolo, com leitura e assinatura do termo de consentimento.

\section{2) Grupos de estudo}

Foram estudados 38 pacientes com CCP, divididos em dois grupos, um deles utilizando cetotifeno $(\mathrm{N}=19)$ e o outro olopatadina $(\mathrm{N}=19)$.
Não houve diferença demográfica, estatisticamente significante, entre os dois grupos. A idade média dos pacientes foi de $8,3 \pm 3,6$ anos (de 2 a 12$)$. Vinte e um por cento $(\mathrm{N}=8)$ eram do sexo feminino e $79 \%$ (N=30) masculino. Vinte e sete $(71,1 \%)$ eram não brancos. No grupo que utilizou olopatadina 10 $(52,6 \%)$ eram da forma palpebral, 7 (36,8\%) límbica e $2(10,5 \%)$ mista. No grupo que utilizou cetotifeno $10(52,6 \%)$ eram da forma palpebral, $6(31,6 \%)$ límbica e 3 (15,8\%) mista.

\section{3) Critérios de inclusão e exclusão}

Os critérios de inclusão deste estudo foram: pacientes sem distinção de etnia ou sexo; história de CCP; presença, pelo menos, de prurido leve e contínuo.

Os critérios de exclusão deste estudo foram: portadores de conjuntivite alérgica, que necessitavam de tratamento sistêmico ou tópico com corticosteróide; portadores de hipersensibilidade conhecida a qualquer um dos componentes da droga do estudo; uso concomitante de outra medicação ocular; uso de lentes de contato 3 dias antes da visita inicial e durante o período do estudo; enfermidades sistêmicas, não controladas, como doenças autoimunes, artrite reumatóide ou doença cardiovascular; tempo mínimo de 14 dias de interrupção do uso de qualquer outra medicação tópica; não comparecimento a todas as avaliações recomendadas no protocolo; outras enfermidades oculares que pudessem interferir nos resultados do estudo como glaucoma de ângulo estreito, conjuntivite folicular e olho seco; sinais e sintomas de inflamação ocular e infecção viral ou bacteriana ativa; gestantes ou lactantes.

\section{4) Critérios para avaliação}

\section{1) Sinais e sintomas}

As informações no protocolo foram documentadas por meio de questionários individuais, em análise seqüencial para cada consulta. As variáveis secundárias de eficácia foram avaliadas pela utilização de graduações padronizadas para sinais e sintomas em todas as visitas.

Os sintomas observados foram prurido, ardor, lacrimejamento, sensação de corpo estranho, secreção e fotofobia (Quadro 1).

Os sinais observados foram hiperemia conjuntival, quemose, edema de pálpebra, presença de papilas na conjuntiva palpebral e presença de pontos de Horner-Trantas (Quadro 2). A ceratite epitelial foi analisada pelo método de coloração: foi instilada 1 gota de fluoresceína $1 \%$ no saco conjuntival, graduando a impregnação dos corantes de $0-9$ pontos $^{(18)}$. Os pacientes foram avaliados por exame biomicroscópico à lâmpada de fenda, nos períodos pré-determinados para pontuação, usando a classificação utilizada em outros estudos ${ }^{(13)}$.

\section{2) Eficácia}

A eficácia global está relacionada à graduação do conforto informado pelos respondedores na $2^{\underline{a}}$ consulta em comparação com condição presente antes do tratamento, na $3^{\underline{a}}$ consulta em relação à $2^{\underline{a}}$ e na $4^{\underline{a}}$ em relação à $3^{\underline{a}}$ (Quadro 3 ). 


\begin{tabular}{|ll|}
\hline \multicolumn{1}{|c|}{ Quadro 1. Graduação dos sintomas } \\
Prurido \\
0 & Ausente \\
1 & Prurido intermitente \\
2 & Prurido contínuo moderado (pode ser localizado), não coça o olho \\
3 & Prurido definitivo, necessidade de coçar o olho \\
4 & Prurido incapacitante, com coceira significante \\
Ardor \\
0 & Ausente \\
1 & Leve (perceptível) \\
2 & Moderado (desconforto) \\
2 & Intenso \\
3 & Muito intenso \\
Lacrimejamento \\
0 & Ausente \\
1 & Leve (sensação de olhos molhados) \\
2 & Moderado (necessidade de limpar os olhos) \\
3 & Intenso (lágrimas escorrem até o queixo) \\
Secreção \\
1 & Ausente \\
2 & Presente \\
Sensação de corpo estranho \\
1 & Ausente \\
2 & Presente \\
Fotofobia \\
1 & Ausente \\
2 & Presente \\
\hline &
\end{tabular}

\begin{tabular}{|c|c|}
\hline \multicolumn{2}{|r|}{ Quadro 2. Graduação dos sinais } \\
\hline \multicolumn{2}{|c|}{ Hiperemia conjuntival } \\
\hline 0 & Ausente (vasos normais) \\
\hline 1 & Leve (discreta injeção vascular definida abaixo do normal) \\
\hline 2 & Moderada (hiperemia ocular difusa) \\
\hline 3 & $\begin{array}{l}\text { Intensa (hiperemia ocular difusa com intensa dilatação dos } \\
\text { vasos conjuntivais) }\end{array}$ \\
\hline \multicolumn{2}{|r|}{ Quemose conjuntival } \\
\hline 0 & Ausente ou não detectável \\
\hline & $\begin{array}{l}\text { Evidente e visível na conjuntiva, elevada, especialmente na } \\
\text { região límbica }\end{array}$ \\
\hline & Abaulamento da conjuntiva \\
\hline \multicolumn{2}{|c|}{ Edema de pálpebra } \\
\hline 0 & Ausente \\
\hline & Leve (pouco edemaciada) \\
\hline & Moderado (edema de pálpebra superior e inferior) \\
\hline & Intenso (pálpebras fechadas, intenso edema) \\
\hline \multicolumn{2}{|r|}{ Papila } \\
\hline 1 & Ausente \\
\hline & Presente \\
\hline \multicolumn{2}{|c|}{ Pontos de Horner-Trantas } \\
\hline & Ausente \\
\hline & Presente \\
\hline & $\begin{array}{l}\text { te: Ganz M, Koll E, Gausche J, Detjen P, Orfan N. Ketotifen fumarate and } \\
\text { patadine hydrochloride in the treatment of allergic conjunctivitis: a real-world } \\
\text { tparison of efficacy and ocular comfort. Adv Ther. } 2003 ; 20(2): 79-91^{(13)} \text {. }\end{array}$ \\
\hline
\end{tabular}

\section{5) Analíse estatística}

Para análise adequada foram utilizados como testes estatísticos:

\begin{tabular}{|c|c|}
\hline \multicolumn{2}{|c|}{ Quadro 3. Graduação do conforto ocular } \\
\hline \multicolumn{2}{|l|}{ Conforto } \\
\hline 0 Excelente & Melhora completa dos sintomas \\
\hline 1 Bom & Moderada melhora \\
\hline 2 Razoável & Pouca melhora \\
\hline 3 Pobre & Sem melhora \\
\hline 4 Deterioração & Piora \\
\hline \multicolumn{2}{|c|}{$\begin{array}{l}\text { Fonte: Ganz M, Koll E, Gausche J, Detjen P, Orfan N. Ketotifen fumarate and } \\
\text { olopatadine hydrochloride in the treatment of allergic conjunctivitis: a real-worl } \\
\text { comparison of efficacy and ocular comfort. Adv Ther. 2003;20(2):79-91(13). }\end{array}$} \\
\hline
\end{tabular}

1) teste "t" não pareado e teste de Mann-Whitney (utilizado para prurido, ardor, lacrimejamento, hiperemia conjuntival, quemose, edema de pálpebra, ceratite e total de sinais e sintomas).

2) teste do qui-quadrado (utilizado para sensação de corpo estranho, papila e pontos de Horner-Trantas).

3) Teste de Fisher (utilizado para secreção e fotofobia).

Para a rejeição da hipótese de nulidade, usamos um valor de $\mathrm{p}<0,05$, simbolizado, quando significante, com um asterisco (*). As médias foram calculadas e apresentadas apenas a título de informação. A freqüência de eventos adversos foi a principal variável de segurança.

\section{RESULTADOS}

As graduações dos sinais e sintomas foram comparadas, entre os grupos, nas quatro visitas.

Em relação à variável total de sinais, que inclui hiperemia conjuntival e quemose, edema de pálpebra e ceratite epitelial, houve melhora progressiva, mas equivalência entre os medicamentos.

Em relação à variável total de sintomas que inclui prurido, ardor e lacrimejamento houve melhora progressiva na segunda, terceira e quarta visitas, entretanto o cetotifeno apresentou superioridade em relação à olopatadina na quarta consulta (Gráfico 1).

A graduação de sinais e sintomas registrados nas visitas foram favoráveis ao cetotifeno em relação à olopatadina com diferenças estatisticamente significantes entre os grupos

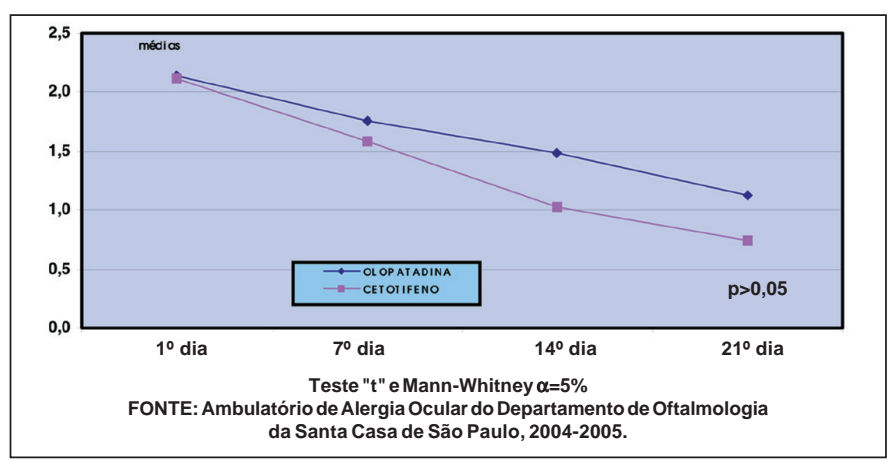

Gráfico 1 - Avaliação dos sinais e sintomas entre os grupos em tratamento com olopatadina e cetotifeno na ceratoconjuntivite primaveril do Ambulatório de Alergia Ocular da Santa Casa de São Paulo, atendidos entre setembro de 2004 e outubro de 2005 
(Quadro 4). Todos os pacientes incluídos no estudo apresentaram melhora dos sintomas ao final do tratamento, independente do grupo analisado.

$\mathrm{Na}$ avaliação da evolução do prurido ocular, observou-se que o cetotifeno proporcionou melhor resultado em relação à olopatadina, a partir do sétimo ao vigésimo primeiro dia de tratamento.

As médias para ardor apresentaram-se entre 2,184 e 0,763 no grupo utilizando olopatadina e entre 2,105 e 0,526 no grupo utilizando cetotifeno. Houve diferença estatisticamente significativa entre segunda e quarta visitas. Observou-se que, a partir do $7^{\circ}$ dia de tratamento, os pacientes em uso da olopatadina tinham menos ardor, em relação aos que fizeram uso do cetotifeno, mas, após o vigésimo primeiro dia, essa relação mostrou-se invertida.

$\mathrm{Na}$ avaliação do lacrimejamento, ambos os medicamentos proporcionaram melhora significante a partir do $1^{\circ}$ dia, com superioridade significante do cetotifeno sobre a olopatadina, entre o $7^{\circ}$ e $14^{\circ}$ dia de tratamento.

O cetotifeno foi eficaz para melhora da hiperemia conjuntival, com superioridade estatisticamente significante em relação à olopatadina a partir do $14^{\circ}$ dia e equivalência a partir do $21^{\circ}$ dia.
Não houve diferença estatisticamente significante entre os grupos tratados com relação à quemose, edema de pálpebra e ceratite epitelial.

Observou-se que, na $2^{\underline{a}}$ e na $4^{\underline{a}}$ consulta os pacientes em uso do cetotifeno queixavam-se menos de secreção, em relação aos que fizeram uso do olopatadina.

Ambos os grupos apresentaram melhora da fotofobia, com superioridade significante do cetotifeno sobre a olopatadina a partir do $7^{\circ}$ dia de tratamento.

Com relação à sensação de corpo estranho, papilas e pontos de Horner-Trantas, não houve diferença estatisticamente significante entre os grupos (Quadro 5).

\section{Eficácia}

Em termos de resposta geral do tratamento (eficácia global) o grupo tratado com cetotifeno demonstrou superioridade estatisticamente significante sobre a olopatadina (Quadro 6).

As médias das graduações apresentaram-se entre 2,263 a 1,842 no grupo utilizando olopatadina e 2,053 a 1,579 no grupo utilizando cetotifeno.

$\mathrm{Na}$ avaliação da eficácia ao tratamento entre os intervalos

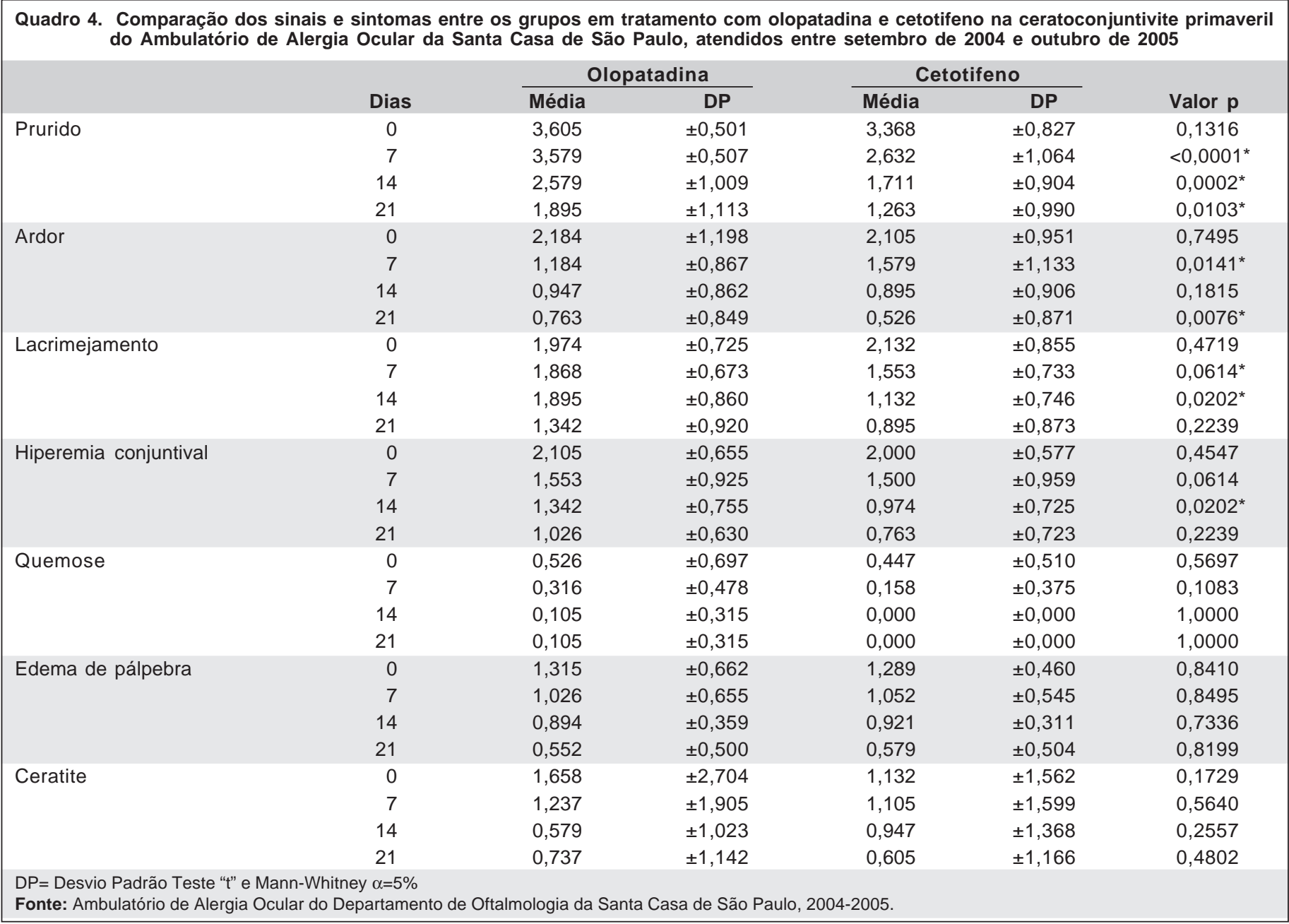




\begin{tabular}{|c|c|c|c|c|}
\hline \multicolumn{5}{|c|}{$\begin{array}{l}\text { Quadro 5. Comparação dos sintomas e sinais entre os grupos em } \\
\text { tratamento com olopatadina e cetotifeno na ceratoconjuntivite } \\
\text { primaveril do Ambulatório de Alergia Ocular da Santa Casa de São } \\
\text { Paulo, atendidos entre setembro de } 2004 \text { e outubro de } 2005\end{array}$} \\
\hline & Dias & $\begin{array}{c}\text { Olopatadina } \\
\text { N (\%) }\end{array}$ & $\begin{array}{c}\text { Cetotifeno } \\
\text { N (\%) }\end{array}$ & Valor $p$ \\
\hline \multirow[t]{4}{*}{ Secreção } & 0 & $34(44,74 \%)$ & $32(42,11 \%)$ & 0,736 \\
\hline & 7 & $34(44,74 \%)$ & $24(31,58 \%)$ & $0,014^{*}$ \\
\hline & 14 & 24 (31,58\%) & $15(19,74 \%)$ & 0,066 \\
\hline & 21 & 24 (31,58\%) & $14(18,42 \%)$ & $0,039^{*}$ \\
\hline \multirow{4}{*}{$\begin{array}{l}\text { Sensação } \\
\text { de corpo } \\
\text { estranho }\end{array}$} & 0 & $26(34,21 \%)$ & $30(39,47 \%)$ & 0,435 \\
\hline & 7 & $28(36,84 \%)$ & $27(35,53 \%)$ & 0,798 \\
\hline & 14 & $23(30,26 \%)$ & $24(31,58 \%)$ & 0,813 \\
\hline & 21 & $22(29,95 \%)$ & $21(27,63 \%)$ & 0,817 \\
\hline \multirow[t]{4}{*}{ Fotofobia } & 0 & 34 (44,74\%) & $34(44,74 \%)$ & 1,289 \\
\hline & 7 & $30(39,47 \%)$ & $20(26,32 \%)$ & $0,030^{*}$ \\
\hline & 14 & 27 (35,53\%) & 17 (22,37\%) & $0,037^{*}$ \\
\hline & 21 & $22(29,95 \%)$ & $18(23,68 \%)$ & 0,491 \\
\hline \multirow[t]{4}{*}{ Papila } & 0 & 24 (31,58\%) & 26 (34,21\%) & 0,808 \\
\hline & 7 & $24(31,58 \%)$ & $25(32,89 \%)$ & 0,810 \\
\hline & 14 & $23(30,26 \%)$ & $23(30,26 \%)$ & 1,000 \\
\hline & 21 & $23(30,26 \%)$ & $24(31,58 \%)$ & 0,813 \\
\hline
\end{tabular}

\begin{tabular}{|c|c|c|}
\hline \multicolumn{3}{|c|}{$\begin{array}{l}\text { Quadro 6. Avaliação da eficácia global entre os grupos em tratamento } \\
\text { com olopatadina e cetotifeno na ceratoconjuntivite primaveril do } \\
\text { Ambulatório de Alergia Ocular da Santa Casa de São Paulo, aten- } \\
\text { didos entre setembro de } 2004 \text { e outubro de } 2005\end{array}$} \\
\hline Olopatadina $(\mathrm{N}=19)$ & Cetotifeno $(\mathrm{N}=19)$ & \\
\hline Média \pm DP & Média \pm DP & Valor $p$ \\
\hline $2,044 \pm 0,846$ & $1,719 \pm 0,793$ & 0,003 \\
\hline \multicolumn{3}{|c|}{$\begin{array}{l}N=\text { número de pacientes; } \mathrm{DP}=\text { desvio padrãoTeste "t" e Mann-Whitney } \alpha=5 \% \\
\text { Fonte: Ambulatório de Alergia Ocular do Departamento de Oftalmologia da Santa } \\
\text { Casa de São Paulo, 2004-2005. }\end{array}$} \\
\hline
\end{tabular}

das visitas, observou-se que ambas as drogas atuaram de forma eficaz, mas o cetotifeno foi superior à olopatadina da segunda para a terceira visita (Gráfico 2).

\section{Efeitos adversos}

Nenhum caso de hipersensibilidade à droga foi observado nos pacientes avaliados. Não houve desistência de pacientes devido o desconforto provocado pela droga. Os eventos adversos mais comuns foram queimação e ardor relatados por dois pacientes utilizando olopatadina. Os resultados da avaliação das reações adversas não evidenciaram diferença significante entre os tratamentos efetuados.

\section{DISCUSSÃO}

Foi realizado um estudo comparativo entre 2 grupos homogêneos, utilizando cetotifeno e olopatadina no tratamento da $\mathrm{CCP}$, análise inédita na literatura pesquisada.

Não houve discordância nos dados relativos à evolução do sintoma principal da CCP, o prurido, entre nossa amostra e a literatura, pois se observou que ambos os medicamentos proporcionaram melhora a partir do $1^{\circ}$ dia $(\mathrm{p}<0,001)$, com superioridade significante do cetotifeno sobre a olopatadina a partir do $7^{\circ}$ dia. Na literatura revisada encontraram melhora do prurido a partir do $1^{\circ}$ dia, mais significante a partir do $5^{\circ}$ e $7^{\circ} \operatorname{dias}^{(13-14)}$.

Observou-se que, a partir do $7^{\circ}$ dia de tratamento, os pacientes em uso de olopatadina tinham menos ardor em relação aos que fizeram uso de cetotifeno, mas, após o $21^{\circ}$ dia, essa relação inverteu-se. Outros estudos relataram que os pacientes em uso da olopatadina tinham menos ardor a partir do $7^{\circ}$ dia, até o término do tratamento ${ }^{(14)}$. Estas queixas podem ser justificadas por incompatibilidade de $\mathrm{pH}$ entre a solução oftálmica e a conjuntiva ${ }^{(19)}$.

Dados relativos à evolução da hiperemia conjuntival, demonstraram que ambos os medicamentos proporcionaram melhora ( $\mathrm{p}<0,001)$, a partir do $1^{\circ}$ dia, com superioridade significante do cetotifeno sobre a olopatadina a partir do $14^{\circ}$ dia. Recentes estudos relataram que, entre o $5^{\circ}$ e $21^{\circ}$ dia, o cetotifeno apresentou, em relação à olopatadina, médias significantemente menores para hiperemia conjuntival, além de todas as médias dos sinais e sintomas no tratamento das conjuntivites alérgicas $^{(13)}$.

Durante o período estudado, a presença de secreção, fotofobia e lacrimejamento apresentaram melhora a partir do $1^{\circ}$ dia, com superioridade significante do cetotifeno sobre a olopatadina a partir do $7^{\circ}$ dia. Equivalência estatística foi demonstrada na associação comparativa individual dos sintomas de secreção, fotofobia e lacrimejamento, na literatura estudada, em outros tipos de conjuntivites alérgicas.

Na comparação da quemose, edema de pálpebra, ceratite epitelial, papilas e pontos de Horner-Trantas, não houve diferença entre os grupos estudados.

$\mathrm{O}$ cetotifeno, em relação à eficácia global ao tratamento, demonstrou superioridade estatisticamente significante sobre a olopatadina. Estudos anteriores também apontaram a superioridade do cetotifeno sobre a olopatadina na conjuntivite alérgica sazonal e nas conjuntivites alérgicas em geral $^{(13-14)}$.

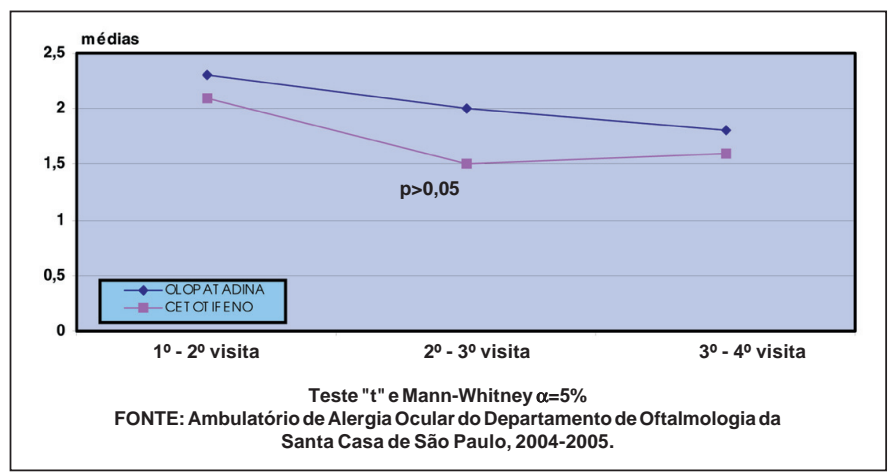

Gráfico 2 - Avaliação do conforto ocular entre os grupos em tratamento com olopatadina e cetotifeno na ceratoconjuntivite primaveril do Ambulatório de Alergia Ocular da Santa Casa de São Paulo, atendidos entre setembro de 2004 e outubro de 2005 s 
Acredita-se que esse resultado provavelmente se deva à presença de mecanismos de ação múltipla e distinta do cetotifeno, que além de bloquear receptores $\mathrm{H} 1$ e $\mathrm{H} 2$ e estabilizar a membrana dos mastócitos apresenta ação inibitória sobre a migração de eosinófilos.

Apenas dois pacientes, que estavam usando olopatadina, queixaram-se de queimação e ardor durante vinte a trinta minutos após a instilação, mas essas queixas diminuíram de intensidade no decorrer do tratamento. Os resultados da avaliação das reações adversas não evidenciaram diferença significante entre os tratamentos efetuados nas tabelas de associação. Não houve desistência ao tratamento devido à intolerância ou efeitos colaterais, tanto para olopatadina ${ }^{(10)}$ como para o cetotifeno $^{(12)}$, o que está de acordo com a literatura analisada.

\section{CONCLUSÕES}

Concluímos que ambas são drogas equivalentes, que atuaram de forma eficaz e segura na remissão dos sintomas relacionados à CCP.

$\mathrm{Na}$ comparação entre o uso tópico de fumarato de cetotifeno $0,025 \%$ e cloridrato de olopatadina $0,1 \%$, utilizando-se tanto o medicamento quanto o tempo como variáveis independentes, podemos concluir que:

1) Em relação à eficácia o grupo tratado com o cetotifeno mostrou melhores resultados do que os tratados com olopatadina.

2) Houve diferença a favor do cetotifeno $(\mathrm{p}<0,05)$ na melhora do prurido, lacrimejamento, hiperemia conjuntival, presença de secreção, fotofobia e ardor no $21^{\circ}$ dia.

3) Houve diferença a favor da olopatadina $(p<0,05)$ na melhora do ardor no $7^{\circ}$ dia.

4) Ambos tratamentos proporcionaram melhora da quemose, edema de pálpebra, ceratite, sensação de corpo estranho, presença de papila e pontos de Horner-Trantas.

\section{ABSTRACT}

Purpose: To compare the topical use of $0.025 \%$ ketotifen fumarate and $0.1 \%$ olopatadine hydrochloride in the treatment of patients with vernal keratoconjunctivitis. Methods: A study performed in one center, simple masked, parallel-group compared ketotifen and olopatadine. These patients were evaluated on four visits during the treatment (days 1, 7, 14 and 21), defined by ratings scores. Adverse events were the main variable of safety rating. Results: On evaluating ocular itching, burning, tearing, conjunctival hyperemia, mucous discharge and photophobia, the ketotifen group showed a significant improvement of total signs and symptoms $(\mathrm{p}<0.05)$. Between the baseline and the $2^{\text {nd }}$ visit, treatment with olopatadine resulted in decreased burning, but after the $4^{\text {th }}$ visit, ketotifen was slightly better. Sand sensation, papillae and Horner-Trantas dots were not significantly different in both groups. Conclusions: Both drugs were efficient and safe relieving the main symptoms and signs of vernal keratoconjunctivitis. Between the same timepoints, there was a significant difference in favor of ketotifen-treated patients $(\mathrm{p}<0.05)$, showing improvement of itching, tearing, conjunctival hyperemia, mucous discharge and photophobia.

Keywords: Conjunctivitis, allergic/drug therapy; Ketotifen/ therapeutic use; Ophthalmic solutions; Dibenzoxepins/therapeutic use; Drug combinations

\section{REFERÊNCIAS}

1. Holzchuh N, Kara-Jose N, Alves MR. Alergia. In: Belfort RJ, Kara-Jose N, editores. Córnea: clínica e cirúrgica. São Paulo: Roca, 1997. p.254-6.

2. Goulart DA, Goulart D, Cypel MC, Dantas PEC, Nishiwaki-Dantas MC Perfil clínico-epidemiológico de pacientes do Ambulatório de Alergia ocular da Santa Casa de São Paulo. Arq Bras Oftalmol. 2003;66(5):609-15.

3. Messmer EM. [Ocular allergies] Ophthalmologe. 2005;102(5):527-43; quiz 544. German.

4. Leonardi A. Emerging drugs for ocular allergy. Expert Opin Emerg Drugs. 2005;10(3):505-20.

5. Bonini S, Coassin M, Aronni S, Lambiase A. Vernal keratoconjunctivitis. Eye. 2004;18(4):345-51.

6. Yanni JM, Sharif NA, Gamache DA, Miller ST, Weimer LK, Spellman JM A current appreciation of sites for pharmacological intervention in allergic conjunctivitis: effects of new topical ocular drugs. Acta Ophthalmol Scand Suppl. 1999;(228):33-7.

7. Abelson MB, Spitalny L. Combined analysis of two studies using the conjunctival allergen challenge model to evaluate olopatadine hydrochloride, a new ophthalmic antiallergic agent with dual activity. Am J Ophthalmol. 1998;125(6):797-804.

8. Abelson MB. Evaluation of olopatadine, a new ophthalmic antiallergic agent with dual activity, using the conjunctival allergen challenge model. Ann Allergy Asthma Immunol. 1998;81(3):211-8.

9. Heyman SN, Karmeli F, Brezis M, Rachmilewitz D. The effect of ketotifen on nitric oxide synthase activity. Br J Pharmacol. 1997;120(8):1545-51.

10. Leonardi A, Abelson MB. Double-masked, randomized, placebo-controlled clinical study of the mast cell-stabilizing effects of treatment with olopatadine in the conjunctival allergen challenge model in humans. Clin Ther. 2003;25 (10):2539-52.

11. Greiner JV, Mundorf T, Dubiner H, Lonsdale J, Casey R, Parver L, et al. Efficacy and safety of ketotifen fumarate $0.025 \%$ in the conjunctival antigen challenge model of ocular allergic conjunctivitis. Am J Ophthalmol. 2003; 136(6): 1097-105.

12. Abelson MB, Ferzola NJ, McWhirter CL, Crampton HJ. Efficacy and safety of single- and multiple-dose ketotifen fumarate $0.025 \%$ ophthalmic solution in a pediatric population. Pediatr Allergy Immunol. 2004;15(6):551-7.

13. Ganz M, Koll E, Gausche J, Detjen P, Orfan N. Ketotifen fumarate and olopatadine hydrochloride in the treatment of allergic conjunctivitis: a realworld comparison of efficacy and ocular comfort. Adv Ther. 2003;20(2):79-91.

14. Höfling-Lima AL, Andrade AJM, Marback PMF, Farah ME, Mascaro V. Comparação do uso tópico de cetotifeno com a olopatadina no tratamento de conjuntivites alérgica. Arq Bras Oftalmol. 2001:64(5):415-22.

15. Leonardi A, Zafirakis P. Efficacy and comfort of olopatadine versus ketotifen ophthalmic solutions: a double-masked, environmental study of patient preference. Curr Med Res Opin. 2004;20(8):1167-73.

16. Aguilar AJ. Comparative study of clinical efficacy and tolerance in seasonal allergic conjunctivitis management with $0.1 \%$ olopatadine hydrochloride versus $0.05 \%$ ketotifen fumarate. Acta Ophthalmol Scand Suppl. 2000(230):52-5.

17. Berdy GJ, Spangler DL, Bensch G, Berdy SS, Brusatti RC. A comparison of the relative efficacy and clinical performance of olopatadine hydrochloride $0.1 \%$ ophthalmic solution and ketotifen fumarate $0.025 \%$ ophthalmic solution in the conjunctival antigen challenge model. Clin Ther. 2000;22(7):826-33.

18. Joyce PD. Corneal vital staining. Ir J Med Sci 1967;6(500):359-67.

19. Bar-Ilan A, Nuemann R. Basic considerations of ocular drug-delivery systems. In: Zimmerman TJ, Kooner KS, Sharir M, Fechtner RD, editors. Textbook of ocular pharmacology. Philadelphia: Lippincott-Raven; 1997. p.139-55. 